\title{
Einleitung und Überblick
}

Thema dieses Buches ist die Risikoaggregation mittels Monte-Carlo-Simulation. Die Risikoaggregation ist die Schlüsseltechnologie im Risikomanagement. Sie ist nämlich nötig, um den Gesamtrisikoumfang und damit den Eigenkapitalbedarf eines Unternehmens zu berechnen. Eine Aggregation der Risiken mit Bezug zur Unternehmensplanung ist auch notwendig zur Erfüllung der gesetzlichen Mindestanforderung an das Risikomanagement: dieses soll nämlich „,bestandsbedrohende Entwicklungen" früh erkennen (§91 AktG) und solche ergeben sich in aller Regel aus Kombinationseffekten von Einzelrisiken. Die Risikoaggregation ist zudem die Grundlage für eine tatsächlich wertorientierte Unternehmensführung, die ein Abwägen erwarteter Erträge und Risiken bei der Entscheidungsvorbereitung ermöglicht. Da Risiken nicht addierbar sind, und im Allgemeinen keine analytische Formel verfügbar ist, um bestehende Einzelrisiken (im Kontext der Unternehmensplanung) zu aggregieren, benötigt man für die Risikoaggregation stochastische Simulationsverfahren, speziell die Monte-Carlo-Simulation. Diese Methode wird im Buch (auch anhand eines ausführlichen Fallbeispiels) erläutert. 